\title{
Pandemia e o colapso do neoliberalismo'
}

\author{
Pandemic and the collapse of neoliberalism
}

\section{Loiane Prado Verbicaro*}

\begin{abstract}
Resumo: $\mathrm{O}$ artigo analisa a pandemia do coronavírus à luz do colapso do neoliberalismo. Os níveis de neoliberalismo no Brasil variaram nos últimos trinta anos e nem mesmo os governos progressistas conseguiram romper com o sistema de acumulação neoliberal implementado no país. Por intermédio de pesquisa bibliográfica de abordagem qualitativa, o artigo apresenta reflexões sobre o neoliberalismo e sua política econômica que favorece a acumulação de capital e a concentração de poder, renda e riqueza, contribuindo para a decomposição da classe trabalhadora, à diluição de formas de solidariedade e a imposição de políticas econômicas e sociais excludentes, com a conversão das democracias sociais em Estados desdemocratizados, com impactos corrosivos na rede de proteção social em tempos de pandemia. Crises epidếmicas ampliam desigualdades e tensões em nossos sistemas, levando-nos a reavaliaçáo dos problemas políticos, econômicos e sociais mais profundos da nossa agenda democrática.
\end{abstract}

Palavras-chave: Pandemia; Neoliberalismo; Crise

Abstract: The article analyzes the coronavirus pandemic in the light of the collapse of neoliberalism. The levels of neoliberalism in Brazil have varied over the past thirty years and not even progressive governments have been able to break with the neoliberal accumulation system implemented in the country. Through bibliographic research with a qualitative approach, the article presents reflections on neoliberalism and its economic policy that favors the accumulation of capital and the concentration of power, income and wealth, contributing to the decomposition of the working class, the dilution of forms of solidarity and the imposition of exclusive economic and social policies, with the conversion of social democracies into undemocratic states, with corrosive impacts on the social protection network in times of pandemic. Epidemic crises increase inequalities and tensions in our systems, leading us to reassess the deepest political, economic and social problems on our democratic agenda.

Keywords: Pandemic; Neoliberalism; Crisis

\section{Introdução}

No Brasil, a defesa neoliberal do "salve-se quem puder" e da "justiça de mercado" goza de expressivo prestígio perante a opinião pública na luta contra a politização e a justiça social corretora do mercado. Esse modelo aumenta a distribuição desigual de renda com impactos na crescente concentração de riqueza entre os mais ricos. Essa tensão e suas tragédias sociais merecem uma reflexão cuidadosa. O Brasil é um dos países mais desiguais do mundo, com uma pobreza negligenciada que reduz a expectativa de inclusão e de acréscimo de cidadania na vida de dezenas de milhões de pessoas. $O$ desenvolvimento econômico brasileiro foi historicamente perverso porque aumentou as desigualdades sociais. Regimes democráticos no Brasil foram fragilmente ensaiados e conciliados com formas autoritárias de neoliberalismo econômico, gerando desengajamento dos processos políticos, com a desmobilização e desarticulação da esfera política de participação, representatividade,

\footnotetext{
${ }^{1}$ Artigo construído a partir de pesquisa realizada no Programa de Pós-doutorado em Filosofia do Direito da Universidade de São Paulo (USP).

*Professora Adjunta da Faculdade de Filosofia e do Programa de Pós-Graduação em Filosofia da Universidade Federal do Pará, Belém, PA. E-mail: loianeverbicaro@uol.com.br ORCID: https://orcid.org/oooo-0002-3259-9906
} 
legitimidade e declínio da política frente ao capital. Anos de enfraquecimento democrático diante de um liberalismo mal engendrado permitiu a ascensão de uma política antidemocrática, com repúdio ao social, o que deixou a população exposta e mal preparada para enfrentar uma crise sanitária tão complexa na escala da pandemia do coronavírus, o que se analisará no artigo desenvolvido por intermédio de pesquisa bibliográfica de abordagem qualitativa.

\section{Pandemia, Desigualdades e Individualismo}

É corrente a ideia segundo a qual a COVID-19 é um vírus que atinge a todos indistintamente. Nesse sentido, o vírus não discriminaria, uma vez que trata a todos com igualdade. No entanto, "nós humanos certaremos o fazemos"2. Trata-se de um mito de que as doenças infecciosas desconhecem classe social ou outros marcadores de desigualdade.

Decerto que os maiores impactos econômicos e sociais serão sentidos mais intensamente pelos mais vulneráveis. As classes mais pobres são sempre as mais afetadas em períodos epidêmicos, pois sentem mais diretamente as consequências da precarização do emprego; da falta de investimento em saúde pública; do apartheid sanitário; do déficit de moradia (favelização da moradia urbana); das condições inadequadas de alimentação e nutrição; da pobreza extrema que faz com que as condições de higiene sejam um luxo não acessível a maior parte da população. Nesse contexto, também importante mencionar que as epidemias geram impactos desproporcionais entre homens e mulheres.

Nesse cenário, vidas são protegidas e outras são jogadas à própria sorte. É a necropolítica 3 das epidemias que, no Brasil, tem um potencial catastrófico. À luz do critério de racionalidade econômica, nota-se a maximização da importância da vida de uns, fazendoos viver, ao lado da exposição, banalização e indiferença das vidas insignificantes, deixandoas morrer. Trata-se da violência estrutural que se articula à forma como as estruturas políticas e econômicas afetam as populações que vivem à margem do sistema.

A economia brasileira é a maior da América Latina e uma das dez maiores do mundo. Mas ao longo da sua história desperdiçou inúmeras oportunidades de implementar uma agenda igualitária e que, ao mesmo tempo, permitisse um reequilíbrio da economia política global. A realidade é que o Brasil é um dos países mais desiguais do mundo, "com uma pobreza totalmente evitável que reduz a expectativa e a qualidade de vida de dezenas de milhões de pessoas"4. O desenvolvimento econômico brasileiro foi historicamente perverso porque aumentou as desigualdades sociais.

Nos intervalos de uma república oligárquica (até 1930), uma ditadura populista de direita (de 1937 a 1945) e uma ditadura militar (1964 a 1985), democracias foram fragilmente ensaiadas. Na década de 1980, a promessa democrática e inclusiva consolidou-se na Constituição brasileira (1988), estruturada sob a base de um Estado de bem-estar social. No entanto, a realização democrática foi limitada, na medida em que o avanço da cidadania ocorreu ao lado da reprodução de uma sub-cidadania e de expressivos privilégios econômicos. A transição para o neoliberalismo fomentou a financeirização do capitalismo e

\footnotetext{
${ }^{2}$ BUTLER, El capitalism tiene sus limites, p. 60.

${ }^{3}$ MBEMBÉ, Necropolítica - biopoder, soberania, estado de exceção política da morte.

4 SAAD FILHO; MORAIS. Brasil: Neoliberalismo versus Democracia, p. 19, 20.
} 
a precarização das condições de vida e trabalho, sobretudo por desconsiderar progressivamente as condições humanas de vida, o acesso democrático à política e limitar o espaço para a distribuição equânime de renda e riqueza baseada na inclusão social e na cidadania.

Os níveis de neoliberalismo variaram nos últimos trinta anos e nem mesmo governos progressistas conseguiram romper com o sistema de acumulação neoliberal herdado dos governos anteriores. Na verdade, ainda que se considere as políticas expansionistas e de distribuição de renda, seus líderes "alienaram as forças sociais que poderiam ter apoiado um projeto transformador" 5 . Destaque-se, no entanto, a versão excepcionalmente excludente do neoliberalismo que realizou-se a partir do governo Temer ao implementar uma agenda de supressão de direitos sociais e contenção dos gastos públicos, a exemplo da Emenda à Constituição no 95, de 2017, que criou o teto de gastos, limitando a capacidade do governo federal de implementar políticas públicas, com especial destaque às políticas do Sistema Único de Saúde (SUS), e realizar política fiscal, diretriz essa seguida e reforçada pelo atual governo federal, com impactos corrosivos na infraestrutura hospitalar após sucessivos desinvestimentos em saúde e na rede de proteção social em tempos de pandemia.

As políticas econômicas que têm sido adotadas criam condições favoráveis à acumulação de capital e concentração de poder, renda e riqueza. Entre as consequências sociais estão a decomposição da classe trabalhadora, a diluição de formas de solidariedade e a imposição de políticas econômicas e sociais excludentes, com a conversão das democracias sociais em Estados desdemocratizados, despojados da soberania do povo e com cidadãos politicamente pacificados.

O que a pandemia tem demonstrado é que a globalização, com seus desdobramentos na intensificação do intercâmbio cultural, na integração dos mercados em escala planetária, com seu intenso fluxo de mercadorias, informação e capital humano, parece agora biologicamente insustentável na ausência de uma infraestrutura social de saúde pública, o que passa pela implementação de políticas sociais e pela construção de um projeto político, econômico e social que ressignifique a regra de ouro da ideologia contemporânea do "eu primeiro"6.

Nessa ideologia, a preocupação com o bem comum é substituída por uma gramática individualista, com posturas apáticas, hedonistas e narcisistas, com o estímulo do "cada um por si" e a identificação da felicidade a partir do consumo, por meio de um processo de individualização das relações sociais em detrimento da alteridade, da solidariedade e de projetos coletivos.

Anos de culto ao individualismo e de liberalismo mal engendrado no Brasil deixaram a população exposta e mal preparada para enfrentar uma crise sanitária tão complexa na escala da pandemia do coronavírus. A política de austeridade fiscal, que acena à inevitabilidade do sacrifício e à hegemonia da esfera financeira sobre as várias dimensões da vida, projetada para financiar cortes de impostos, de benefícios sociais e de direitos; bem como a descontinuidade de programas e pesquisas científicas em razão das reiteradas reduções orçamentárias às universidades e do descrédito com a educação; e paradoxalmente, para conceder subsídios às empresas, tornou-se incompatível com a promessa democrática de inclusão socioeconômica.

5 SAAD FILHO; MORAIS. Brasil: Neoliberalismo versus Democracia, p. 22.

${ }^{6}$ BADIOU, La situación epidémica. 
Em tempos de pandemia, os arautos da racionalidade econômica dos mercados têm defendido que "pior que o medo da epidemia deve ser o medo do desemprego", afinal "o engenho não pode parar", ainda que custe a vida de milhares de indivíduos. A vida humana é instrumentalizada pelo mercado, minimizada e vista como o suprimento "descartável para que o processo de acumulação e concentração não pare". Trata-se, segundo Safatle, de um necroestado nacional ou, em referência a Paul Virilio, de um Estado suicidário, como aquele que flerta com a sua própria destruição, constituindo essa realidade como um novo estágio nos modelos de gestão do neoliberalismo7 ${ }^{7}$

Diante de uma crise sem precedentes e de reviravolta na ordem política e econômica global, fica evidente o momento de inflexão impostergável sobre as políticas sociais e econômicas implementadas no pais. A crise oferece uma oportunidade extraordinária para reflexão e revisão do status quo, bem como um argumento poderoso em favor da assistência universal à saúde, com o fortalecimento da arquitetura de saúde pública; e da reavaliação dos problemas mais profundos de nossas sociedades, que passa pela implementação de uma agenda igualitária; pela defesa das universidades públicas e dos investimentos em pesquisa científica; e de uma rede de proteção social que estabeleça condições de resgate dos valores democráticos, da emancipação e liberdade, permitindo às pessoas exercerem suas potencialidades legítimas.

\section{A Insuficiência do Neoliberalismo para Construção de uma Rede de Solidariedade e Proteção Social}

O neoliberalismo é uma ideologia econômica e social que define um modelo de mercado, o papel do Estado, a maneira de interação e adequação da sociedade e do indivíduo à dinâmica de mercado. Promove uma forte defesa do livre mercado como arena de concorrência, com vista à máxima eficiência e êxito competitivo. Esse modelo concorrencial espraia-se para todas as esferas da vida, determinando que os indivíduos vejam-se como empresas de máxima performance.

Começou a desenvolver-se nos anos 30 e 40, no colóquio "Walter Lippmann” em 1938, que reuniu acadêmicos liberais para discutir as mudanças político-intelectuais do liberalismo com as ameaças do socialismo. Nos anos 70 e 80 começa a ser colocado em prática após a crise do petróleo, como alternativa para recuperar a economia em crise. $\mathrm{O}$ marco de realização do neoliberalismo enquanto modelo econômico e social de Estado foi a eleição de Margareth Thatcher em 1979 como Primeira-Ministra da Inglaterra (1979-1990) e o governo de Ronald Reagan (1981-1989) como presidente dos Estados Unidos, muito embora a primeira experiência essencialmente neoliberal tenha ocorrido no governo ditatorial de Augusto Pinochet no Chile, ao longo da década de 70. Em 1989, com o Consenso de Washington, os ajustes macroeconômicos propostos por economistas de instituições financeiras como o Fundo Monetário Internacional (FMI), Banco Mundial e Departamento do Tesouro dos EUA foram ampliados aos países em desenvolvimento que passavam por dificuldades econômicas, com propostas de ajustamento estrutural de privatização do Estado, redução da função pública, desmobilização sindical, desmonte da solidariedade social, financeirização da economia e corrosão da democracia, com o

7 SAFATLE, Bem-vindo ao Estado Suicidário. 
consequente enfraquecimento da autonomia política na tomada de decisão, considerando a supremacia do capital financeiro que controla os centros de decisão em escala mundial.

Quanto aos seus autores, destacam-se os principais representantes da escola austríaca, Ludwig Von Mises "Liberalismo" e Friedrich Hayek "Caminho da Servidão" e da escola americana de Chicago Milton Friedman. Há inúmeras variações e interpretações dessas teorias e de desdobramentos, a exemplo do libertarianismo de Robert Nozick e sua suposta teoria da justiça, que defende ampla liberdade de mercado com rígidos limites ao uso do Estado para fins de política social e oposição aos esquemas de tributação redistributiva; e um capitalismo irrestrito sem compromissos sociais como o único capaz de garantir trocas livres e a posse de si.

Segundo Harvey, o neoliberalismo é uma teoria econômico-política que propõe que o bem estar humano pode ser potencializado libertando as liberdades empreendedoras e talentos individuais a partir de um quadro institucional caracterizado por fortes direitos de propriedade, mercado e comércio livre ${ }^{8}$ e, nesse sentido, a questão social é repudiada pelo neoliberalismo, por minar a liberdade com uma agenda tirânica de igualdade social. $\mathrm{O}$ ataque neoliberal às políticas sociais gera uma cultura anti-democrática. Segundo Wendy Brown, a racionalidade neoliberal tem êxito em fazer desaparecer os poderes sociais, as reivindicações críticas, com a consequente despolitização da vida pública ${ }^{9}$.

Ao contrário do Estado mínimo do liberalismo clássico que recorria ao modelo econômico do laissez-faire e ao modelo político de vigia noturno, o Estado neoliberal não é mínimo. O Estado continua agindo fortemente por meio de uma atuação vigilante e permanente a favor do mercado. Há nos governos neoliberais uma ação forte e estratégica, de efeito potencializador, em favor dos capitais. Trata-se de um intervencionismo de mercado que intervém quando convém à economia e, ao mesmo tempo, trava a realização de exigências sociais: a ele cabe investir em infraestrutura para o estímulo ao mercado, efetuar a manutenção do câmbio da moeda, o controle das flutuações inflacionárias e da taxa de juros para a garantia da estabilidade econômica, ademais de, em momentos de crise, transferir para os cidadãos os custos da recuperação do sistema financeiro. Nesse sentido, se setores estratégicos apresentarem sinais de instabilidade, o Estado os socorre, bancando os riscos da atividade econômica, afinal, são "too big to fail" e, portanto, dignos de ajuda estatal, ainda que isso represente um keynesianismo de resgate dispendioso às custas das massas empobrecidas. Os mercados competitivos são bons, mas não são exatamente naturais nem autossuficientes. Nesse cenário, é imperioso perguntar: Estado mínimo para quem?

Para Pierre Dardot e Christian Laval, a razão neoliberal apresenta quatro traços característicos: o mercado apresenta-se não como um dado natural, como sustentavam os economistas clássicos, mas a partir de uma realidade construída que requer a intervenção ativa do Estado, assim como um sistema de direito específico. Dessa forma, o discurso neoliberal não realiza-se à luz de uma ontologia da ordem mercantil, pois não busca o fundamento de sua legitimidade no "curso natural das coisas". Trata-se de um "projeto construtivista"; a essência da ordem de mercado reside não na troca, mas na concorrência. Dessa forma, a existência do mercado implica em fazer valer a concorrência como norma geral das práticas econômicas; o Estado vê-se a si mesmo como empresa, tanto em seu funcionamento interno, como em sua relação com outros Estados. Nesse cenário ocorre uma

\footnotetext{
${ }^{8}$ HARVEY, A Brief History of Neoliberalism.

9 BROWN, Nas ruínas do neoliberalismo: a ascensão da política antidemocrática no ocidente, p. 54.
} 
primazia do direito privado e um esvaziamento das categorias do direito público. Nota-se uma conformação da ação pública aos critérios de rentabilidade, produtividade, eficiência, desempenho, com ênfase à vida apolítica do cidadão-consumidor indiferente e apático; a universalização da norma da concorrência ultrapassa as fronteiras do Estado, atingindo os indivíduos em suas relações. Trata-se de uma nova subjetivação imposta pelo neoliberalismo. A governamentalidade empresarial que prevalece no plano da ação do Estado (Estado-empresa) espraia-se para a ideia de indivíduos empreendedores de si (sujeito-empresa), sem garantias e estabilidade. A empresa passa a constituir-se em modelo de subjetivação ${ }^{10}$; "cada indivíduo é uma empresa que deve se gerir e um capital que deve se fazer frutificar"1.

A partir dessas características, nota-se a extensão da racionalidade mercantil e gerencial a todas as esferas da existência humana, fazendo da razão neoliberal uma verdadeira razão-mundo que acena ao esgotamento da ideia de democracia como norma política, ao subverter a concepção de cidadania ligada à proteção social como consequência lógica da democracia política. Não se trata de um simples desencantamento democrático passageiro, mas de uma mudança radical e de uma dessimbolização que afeta o modo de fazer política.

Nesse cenário, a figura do cidadão dá lugar ao homem empreendedor, o sujeito ao qual a sociedade nada deve, aquele que tem que se esforçar para conseguir o que quer, de acordo com os valores da meritocracia. A referência da ação política não é mais o sujeito de direitos, mas um ator autoempreendedor que é o único responsável pelo empreendimento de si. O político passa a enfatizar a lógica da racionalidade econômica. Nesse sentido, não se governa um povo. Regula-se o fluxo de populações, fazendo viver quando se agrega riqueza e capital ao país; e deixando morrer pela improdutividade ou pouca capacidade de consumo. Esse modelo atenta diretamente contra a lógica democrática da cidadania social, "reforçando as desigualdades sociais na distribuição dos auxílios e no acesso aos recursos em matéria de emprego, saúde e educação" ${ }^{2}$. Trata-se da fabricação de um número crescente de "subcidadãos" e "não cidadãos".

Outro aspecto dessa nova razão de mundo é a aproximação entre o neoliberalismo e o neoconservadorismo de teor altamente moralizador. Na realidade, "entre neoliberalismo e neoconservadorismo existe uma concordância que não é nada fortuita: se a racionalidade neoliberal eleva a empresa a modelo de subjetivação, é simplesmente porque a formaempresa é a 'forma celular' de moralização do indivíduo trabalhador', da mesma forma que a família é a 'forma celular' da moralização da criança.” Daí a exaltação do indivíduo calculador e responsável que acompanha indiferente o desmantelamento dos sistemas de aposentadoria, educação pública e saúde. Nesse sentido, mais do que uma singela zona de contato, "a articulação da empresa com a família é o ponto de convergência ou interseção entre normatividade neoliberal e moralismo conservador"13.

No Brasil, o liberalismo conviveu por anos com a escravidão. Agora temos um liberalismo de mercado ao lado de um autoritarismo nos costumes que leva o Estado a um

\footnotetext{
10 Trata-se da ideia de horizonte utópico do neoliberalismo com a perspectiva da humanização pelo trabalho que leva ao empreendedor de si e ao homem de consumo, que produz a sua própria satisfação. CHAVES, Homo Economicus e o empresário de si: subjetivações (im) postas pelo neoliberalismo.

${ }^{11}$ DARDOT, LAVAL, A Nova Razão do Mundo. Ensaio sobre a Sociedade Neoliberal, p. 378.

${ }^{12}$ DARDOT, LAVAL, A Nova Razão do Mundo. Ensaio sobre a Sociedade Neoliberal, p. 381.

${ }^{13}$ DARDOT, LAVAL, A Nova Razão do Mundo. Ensaio sobre a Sociedade Neoliberal, p. 388.
} 
patrulhamento sobre os planos de vida individuais. Isso contraria os princípios do individualismo, da tolerância e da neutralidade ética do Estado que são ideias estruturais do liberalismo. Nesse sentido, o neoliberalismo é profundamente iliberal.

Nesse modelo de exaltação da liberdade mercadológica, há um esvaziamento da democracia participativa, provocado tanto pela demonização da política e dos esquemas de justiça estatal, conduzidas pela asfixia econômica e financeira, como pelo investimento na crença da inevitabilidade, é dizer, de que não há alternativa ao status quo, o que gera passividade e apatia. Trata-se da criação de um "novo normal" social marcado por um tempo sem alternativas, que fixa padrões de integração, representação e mecanismos de controle social vinculados a uma lógica de austeridade marcada pelo conformismo face às privações relativas a bens materiais e simbólicos ${ }^{14}$. Com a política da desesperança e da falta de alternativa, as eleição deixam de fazer diferença, sobretudo aos olhos daqueles que mais necessitam de mudanças políticas. Conforme análise do sociólogo econômico Wolfgang Streeck, "a resignação política das camadas desfavorecidas protege o capitalismo contra a democracia e estabiliza a transição neoliberal que lhe dá origem"15.

Nesse novo normal, a preocupação com o "bem comum" é substituída por uma gramática individualista, com posturas apáticas, hedonistas e narcisistas. Estimula-se o "cada um por si" e a identificação da felicidade a partir do consumo ${ }^{16}$, por meio de um processo de individualização das relações sociais (atomização dos indivíduos) em detrimento da solidariedade e de projetos coletivos. A alteridade entra em crise em sociedades narcísicas e ensimesmadas. Vê-se uma homogeneização do indivíduo numa lógica que atende aos imperativos do mercado e o desaparecimento do cuidado com o outro diante da exaltação e da ditadura do eu como subjetivação que nega o comum ou preocupações para além daquelas inerentes ao próprio desempenho e à competitividade.

Hoje, vê-se, no Brasil, o avanço do retrocesso, com a degradação das condições de trabalho e a retirada de direitos trabalhistas; o antiambientalismo; o discurso refratário aos direitos humanos e aumento da força policial, tendo a morte como política de Estado (necropolítica), que tanto faz morrer (guerra às drogas, à criminalidade), quanto deixa morrer sem as proteções sociais estatais; o corte de políticas sociais distributivas; a negação de pautas identitárias, o que provoca a intensificação da vulnerabilidade de minorias excluídas historicamente como índios, quilombolas, negros, LGBTs e imigrantes; ataques e ameaças à veículos de imprensa, afinal, a imprensa desafia a ilusão do consenso; a intimidação, perseguição e censura aos professores (combate ao marxismo cultural); a deterioração das instituições educacionais, universitárias e científicas; o cultivo do antiintelectualismo, revisionismo histórico, negacionismo científico e contrário ao politicamente correto; a demonização do Estado e privatização das empresas públicas.

A história reitera o embate entre tentativas de inclusão econômica e social da massa empobrecida e a resistência da plutocracia econômica e financeira, conduzida pela lógica da eficiência econômica e por obstáculos intrínsecos ao projeto democrático. Nesse contexto, é imperioso afirmar que o neoliberalismo aprofunda as desigualdades sociais, inviabilizando a construção de uma rede de proteção social. A pandemia lançou ainda mais luzes à insuficiência do neoliberalismo. É imperativo recuperar a centralidade do debate sobre políticas de proteção social que, dentre outras defesas, promova a saúde como um bem

\footnotetext{
${ }^{14}$ Sobre o assunto, ver: FERREIRA, Política e Sociedade. Teoria social em tempo de austeridade.

${ }^{15}$ STREECK, Tempo Comprado. A crise adiada do capitalismo democrático, p. 102.

${ }^{16}$ LIPOVETSKY, O Império do Espetáculo e do Divertimento.
} 
público, considerando a importância do corpo social para a realização da saúde e dos direitos sociais como um projeto coletivo de democracia.

\section{Conclusão}

O artigo lançou algumas reflexões sobre a pandemia do coronavírus à luz do colapso do neoliberalismo e de sua inviabilidade na construção de uma rede de proteção social. A política de austeridade fiscal, projetada para financiar cortes de programas sociais e de pesquisas científicas, promover flexibilização de direitos e conceder subsídios às empresas, acentua a vulnerabilidade dos mais excluídos da sociedade, sendo incompatível com uma agenda baseada na igualdade.

Períodos de crises extremas, como a pandemia da COVID-19, são momentos de inflexão impostergável, de reavaliação dos problemas mais profundos de nossas sociedades e de mudanças no status quo, o que nos leva a refletir sobre a importância do valor democrático e de políticas sociais e econômicas necessárias para romper com o sistema que reiteradamente legaliza privilégios e legitima desigualdades, com ampliação da iniquidade e fratura social.

A pandemia da COVID-19 reforça a urgência do amparo humanitário; da solidariedade internacional; a necessidade da assistência universal à saúde, com o fortalecimento da arquitetura de saúde pública; da implementação de uma agenda igualitária; da defesa das universidades públicas, dos investimentos em pesquisa e confiança na ciência; e da construção de uma rede de proteção social que acene à realização de promessas não cumpridas e estabeleça condições de resgate dos valores democráticos, da emancipação e liberdade, permitindo às pessoas exercerem suas potencialidades legítimas.

Encerro o texto admitindo o caráter controverso e disputado das minhas ideias e argumentos e, nesse sentido, abro à possibilidade de refutação e crítica.

\section{Referências}

ADORNO, Theodor W. Educação e Emancipação. Rio de Janeiro: Paz e Terra, 2008.

AGAMBEN, Giorgio. La invención de uma epidemia. In: Sopa de Wuhan: Pensamiento Contemporáneo en Tiempos de Pandemias. Buenos Aires: Pablo Amadeu Editor. Editorial ASPO (Aislamiento Social Preventivo y Obligatorio), 2020.

BADIOU, Alain. La situación epidémica. In: Sopa de Wuhan: Pensamiento Contemporáneo en Tiempos de Pandemias. Buenos Aires: Pablo Amadeu Editor. Editorial ASPO (Aislamiento Social Preventivo y Obligatorio), 2020.

BIHR, Alain. França: pela socialização do aparato de saúde. In: DAVIS, M., et al. Coronavírus e a luta de classes. Brasil: Terra sem Amos, 2020.

BROWN, Wendy. Nas ruínas do neoliberalismo: a ascensão da política antidemocrática no ocidente. São Paulo: Editora Filosófica Politéia, 2019.

BUTLER, Judith. El capitalism tiene sus limites. In: Sopa de Wuhan: Pensamiento Contemporáneo en Tiempos de Pandemias. Buenos Aires: Pablo Amadeu Editor. Editorial ASPO (Aislamiento Social Preventivo y Obligatorio), 2020. 
CHAVES, Ernani. Homo Economicus e o empresário de si: subjetivações (im) postas pelo neoliberalismo. In: Aula Inaugural. Filosofia UNISINOS, 2018.

DARDOT, Pierre; LAVAL, Christian. A Nova Razão do Mundo. Ensaio sobre a Sociedade Neoliberal. São Paulo: Boitempo, 2016.

DAVIS, M., A crise do coronavírus é um monstro alimentado pelo capitalismo. In: Davis, M., et al. Coronavírus e a luta de classes. Brasil: Terra sem Amos, 2020.

FERREIRA, António Casimiro. Política e Sociedade. Teoria social em tempo de austeridade. Porto: Vida Económica, 2016.

HAN, Byung-Chul. La emergência viral y el mundo de mañana. In: Sopa de Wuhan: Pensamiento Contemporáneo en Tiempos de Pandemias. Buenos Aires: Pablo Amadeu Editor. Editorial ASPO (Aislamiento Social Preventivo y Obligatorio), 2020.

HARVEY, David. A Brief History of Neoliberalism. Oxford University Press, 2005.

HARVEY, David. Política anticapitalista em tempos de COVID-19. In: Davis, M., et al. Coronavírus e a luta de classes. Brasil: Terra sem Amos, 2020.

HAYEK, Friedrich. Camino de Servidumbre. Madrid: Alianza Editorial, 2011.

HOLSTON, James. Cidadania Insurgente. Disjunções da democracia e da modernidade no Brasil. São Paulo: Companhia das Letras, 2013.

LIPOVETSKY, Gilles. O Império do Espetáculo e do Divertimento. In: Lipovetsky, Gilles; SERROY, Jean. A Estetização do Mundo: Viver na Era do Capitalismo Artista. São Paulo: Companhia das Letras, 2015.

MBEMBÉ, Achille. Necropolítica - biopoder, soberania, estado de exceção política da morte. Arte $\mathcal{E}$ Ensaios. Revista do PPGAV/EBA/UFRJ. n. 32 dezembro, 2016.

MISES, Ludwig Von. Liberalismo. São Paulo: Instituto Von Mises, 2010.

NOZICK, Robert. Anarquia, Estado e Utopia. São Paulo: Martins Fontes, 2011.

SAAD FILHO, Alfredo; MORAIS, Lecio. Brasil: Neoliberalismo versus Democracia. São Paulo: Boitempo, 2018.

SAFATLE, Vladimir. Bem-vindo ao Estado Suicidário. In: O Jornal de Todos os Brasis. Publicado na Edição de 25 de março de 2020.

SANTOS, Wanderley Guilherme. A Democracia impedida. O Brasil no século XXI. Rio de Janeiro: FGV, 2017.

SCHWARCS, Lilia. 100 dias que mudaram o mundo. Entrevista publicada no Universa, em 5 de abril de 2020.

STREECK, Wolfgang. Tempo Comprado. A crise adiada do capitalismo democrático. São Paulo: Boitempo, 2018.

ZIBECHI, Raúl. Coronavírus: a militarização das crises. In: Davis, M., et al. Coronavírus e a luta de classes. Brasil: Terra sem Amos, 2020.

ZIZEK, Slavoj. El coronavirus es um golpe al capitalismo a lo Kill Bill. In: Sopa de Wuhan: Pensamiento Contemporáneo en Tiempos de Pandemias. Buenos Aires: Pablo Amadeu Editor. Editorial ASPO (Aislamiento Social Preventivo y Obligatorio), 2020. 